\title{
Currículo em tempos difíceis
}

\author{
Curriculum in hard times
}

\author{
Lucíola Licinio Santos*
}

\begin{abstract}
Resumo
O objetivo deste artigo é mostrar como o campo do currículo, principalmente a partir dos anos 1990, influenciou propostas de mudança na educação brasileira, e como foi perdendo gradativamente essa influência. Argumenta-se que, hoje, a parcela da produção que sofre a influência de algumas vertentes dos estudos culturais não mais oferece contribuições efetivas para a prática pedagógica das escolas. 0 artigo está dividido em duas partes. A primeira mostra como, sob a influência das teorias críticas, a produção no campo do currículo teve grande repercussão nas propostas das reformas educacionais, durante a década de 1990. Na segunda parte, com base em Terry Eagleton, é feita uma crítica à vertente dos estudos culturais que trabalha dentro de um referencial pósmodernista. Nesse contexto, é discutida a razão de os estudos curriculares, que se introduzem dentro dessa orientação, estarem oferecendo poucas contribuições para o currículo escolar.
\end{abstract}

Palavras-Chave: Produção Curricular Crítica; Pós-Modernismo e Currículo; Teoria Curricular e Educação Escolar

\section{Abstract}

The aim of this paper is to show how the curriculum field, mainly since the 1990s, influenced proposals of change within Brazilian education and why later this influence gradually decreases. It is argued that nowadays a significant part of the production in the curriculum field is influenced by postmodernist cultural studies. It is also argued that this orientation is not able to offer effective contributions to the pedagogical practice. The article is divided in two parts. The first one shows how, under the influence of critical theories, the production in the curriculum field had a wide repercussion in the educational reforms during the 1990s. In the second part, based on Terry Eagleaton' ideas, it is criticized the postmodernist cultural studies approaches. In this context, it is discussed why postmodernist curriculum studies have given a small contribution to school curriculum.

Keywords: Critical Curriculum Academic Production; Postmodernism and Curriculum; Curriculum Theory and School Education

Professora da Faculdade de Educação da Universidade Federal de Minas Gerais (UFMG). Belo Horizonte (Brasil). luciola@fae.ufmg.br. 
O objetivo deste artigo é mostrar como o campo do currículo, principalmente a partir dos anos 1990, influenciou propostas de mudança na educação brasileira, e como foi perdendo gradativamente essa influência. Argumenta-se que, hoje, a parcela da produção que sofre a influência de algumas vertentes dos estudos culturais não mais oferece contribuições efetivas para a prática pedagógica das escolas.

A produção na área do currículo no Brasil avançou bastante, desde que Moreira (1990) mapeou a emergência e o desenvolvimento do campo, no início dos anos 1990. A tendência crítica, predominante na área na década passada, procurou analisar e diagnosticar problemas, bem como elaborar sugestões e recomendações, com vistas à superação de crônicos problemas presentes no currículo escolar. Nesse período, buscando tornar a educação mais democrática, evitando que a escola continuasse a legitimar diferenças e assimetrias sociais e culturais, ampliou-se a produção e as atividades do campo com a publicação de artigos, realização de seminários e conferências e a prestação de assessoria às redes de ensino.

Nesse contexto, foram criticados os currículos disciplinares; a hegemonia da cultura acadêmica nos conteúdos curriculares; a hierarquização de disciplinas, no interior das propostas curriculares; as discriminações de classe, gênero e etnia presentes tanto nos currículos oficiais como nos materiais didáticos e nas práticas escolares. Multiplicaram-se os trabalhos que defendiam os currículos integrados; a necessidade de conhecimento das culturas dos alunos; o respeito às diferenças culturais; a aproximação do currículo da vida cotidiana e da cultura da comunidade em que a escola se insere; a necessidade de a escola trabalhar não apenas conteúdos cognitivos, mas também valorizar e trabalhar o corpo, as emoções e as habilidades e valores sociais; a reorganização da sala de aula, no sentido do estabelecimento de práticas mais democráticas de ensino e o uso de materiais variados no ensino. Além disso, foi também discutida a influência do currículo na formação das subjetividades dos alunos, em função não apenas dos conteúdos ministrados, mas também das formas de ensino utilizadas.

Um balanço da influência desses discursos na prática das escolas mostra a integração de grande parte dessas idéias. O método de projetos ganhou destaque, na busca de superar a organização e as hierarquias disciplinares e de conectar melhor o currículo com os problemas da vida 
cotidiana. Atividades de arte, envolvendo as artes plásticas, o teatro, a dança e a música, com ênfase na produção da cultura popular, começaram a ter maior espaço nos currículos escolares. Evidências dessas mudanças podem ser vistas no conteúdo dos Parâmetros Curriculares Nacionais e também nas propostas de reformas curriculares elaboradas por diferentes estados e municípios para suas redes de ensino.

Esse quadro promissor, essa crença no poder das reformas das redes públicas é desestabilizada na presente década, quando são divulgados os resultados das avaliações de desempenho da escola básica. Nesse sentido, a educação tem recebido especial destaque na mídia, e a escola pública tem sido criticada por não conseguir, nem ao menos, que a maioria de seus alunos tenha um domínio razoável da leitura e da escrita.

Por que essas novas propostas, essa série de mudanças e de cursos tiveram tão pouco impacto nas escolas? Se por um lado, há críticas quanto à dificuldade da escola em se atualizar aos novos tempos e de responder satisfatoriamente a todas as demandas que lhe são postas, por outro lado, há também críticas relativas à falta de uma clara orientação e organização pedagógica por parte das escolas.

É inegável que, hoje, algumas escolas buscam transformar essa "triste realidade pedagógica", trazendo para seu interior oficinas de música, teatro e dança. São muitas as demandas postas para a escola - ela é cobrada a fornecer educação para diversas questões sociais e culturais, além de ter que resolver problemas mais imediatos decorrentes da realidade em que se insere, o que inclui a violência, as drogas, o sexo precoce e tantos outros. Nesse sentido, dilata-se o currículo escolar, com um grande ativismo no interior das escolas, buscando enfrentar todos esses desafios. No entanto, há queixas de que as atividades consideradas, até pouco tempo, como basicamente escolares (por exemplo, o ensino da leitura e da escrita, da matemática, da história, da geografia e das ciências) têm sido prejudicadas pela ampliação e multiplicação de conhecimentos, habilidades de diversas ordens e formas de comportamento, que foram assumidos como integrantes do currículo escolar. Diante dessa situação, pode-se argüir se as transformações sociais e culturais não exigiriam uma nova escola e, portanto, novos currículos.

O que se pode observar é que há uma grande tensão quando se pensa nos currículos escolares, atualmente, no Brasil. Como modificar a educação escolar de forma a tornar a escola mais inclusiva, mais acolhedora, em relação às crianças e adolescentes das camadas populares, 
garantindo, ao mesmo tempo, melhor desempenho nos testes estaduais e nacionais? Abre-se mão das novas atividades, das práticas lúdicas introduzidas nas escolas? Volta-se a trabalhar com o currículo disciplinar? Como trabalhar com um currículo mais integrado, na forma de projetos, de maneira a possibilitar, ao mesmo tempo, organização e sistematização dos conteúdos estudados?

Essas perguntas parecem despertar pouco interesse em um grupo crescente de acadêmicos. As discussões sobre currículo escolar parecem, nestes últimos anos, e para algumas tendências no campo do currículo, alguma coisa fora de lugar e datada. De maneira bem direta e simples, parece que fica quase impossível, para alguns, aprofundar problemas presentes nos currículos escolares, sem ser prescritivo, e para outros, sem ser moralista, essencialista e metafísico. Em meio a esses extremos, há sempre a maioria silenciosa. ${ }^{1}$

Se para os primeiros, operacionalizar idéias tem um duplo perigo, ou seja, corre-se o risco de se cair em erros, ou de estar se envolvendo em atividades "menos nobres", que comprometem posições e prestígio no campo acadêmico, de forma diferente; para o segundo grupo, discutir os reais problemas dos currículos escolares, dando respostas às demandas das escolas, significaria adentrar em questões como seleção e organização de conteúdos. Tarefa esta, bem arriscada, que pode levantar questões de pertinência, relevância e qualidade, problemas que se colocam no campo de valores e de juízos morais. Problemas estes já ultrapassados, para este grupo, e compartilhados apenas, no seu ponto de vista, por intelectuais que acreditam que é possível definir quais são as melhores alternativas, como se existisse alguma garantia para isso. Falar em currículo implica em pensar e analisar criticamente o que as escolas estão fazendo ou o que pretendem fazer. Para este grupo, como não há certezas objetivas que assegurem o que é melhor e pior, não há como trabalhar nessa perspectiva.

Além disso, a escola torna-se um assunto sem grande apelo acadêmico, quando as experiências fora dela parecem mais vibrantes, o que vem atraindo o interesse de um número considerável de intelectuais da própria educação. A emergência de campos novos de trabalho para o educador, fora das instituições escolares, cresce com a multiplicação das

1 Essa maioria silenciosa só toma partido quando a vitória é certa e, por isso, tende a seguir as idéias daqueles que se colocam ou são colocados como tendo prestígio no campo. 
ONGs e de programas sociais geridos pelas iniciativas pública e privada. O potencial desse novo mercado se combina com a possibilidade de se trabalhar com novos campos de investigação. A demanda real e potencial desses novos campos de atuação se conjuga com disputas no interior do campo acadêmico (Bourdieu, 1996 e 2004), tornando "educação em espaços não-escolares” uma temática extremamente atrativa. É impressionante como nas próprias faculdades de educação (elas mesmas instituições escolares), nos programas de curso, nos temas de palestras e seminários tornam-se cada vez mais presentes expressões como "educacionais não-escolares" ou em "espaços não-escolares”. Assim, falar de currículo escolar coloca-nos diante de um grande desafio. Como abordar essa temática sem parecer um burocrata do sistema, disposto a criar mais normas e regras, sem prestar atenção em como elas funcionam e por que funcionam ou não? Como falar de um tema como esse sem parecer fora de moda? sem cair em discursos fundamentalistas, em metanarrativas e verdades absolutas?

\section{Estudos CULTURAIS E CURRÍculo}

Com base em Eagleton (2005), ${ }^{2}$ nesta seção, busca-se fazer algumas observações sobre uma nova tendência no campo do currículo, evidenciando seus avanços e limites para a teoria e para a prática curricular. $\mathrm{O}$ argumento central é de que se em sua primeira fase a penetração dos estudos culturais promoveram avanços no campo do currículo, na fase atual perderam seu caráter mobilizador e crítico, ${ }^{3}$ não mais oferecendo reflexões, idéias e perspectivas que façam avançar o currículo escolar.

É preciso registrar que, nesta parte do artigo, são exploradas algumas idéias de Eagleton (2005) e um pouco de sua ironia que confluem e fazem eco a pontos de vista e sentimentos da autora. Há, portanto, uma

2 Terry Eagleton trabalha, na Universidade de Manchester, com crítica literária e tem vários livros publicados em português.

3 O que está sob ataque no livro de Eagleton (2005) são alguns aspectos do que ele chama de pós-modernismo. Em suas palavras, “pós-moderno quer dizer, aproximadamente, o movimento de pensamento contemporâneo que rejeita totalidades, valores universais, grandes narrativas históricas, sólidos fundamentos para a existência humana e a possibilidade de conhecimento objetivo. O pós-modernismo é cético a respeito de verdade, unidade e progresso, apõe-se ao que vê como elitismo na cultura, tende ao relativismo cultural e celebra o pluralismo, a descontinuidade e a heterogeneidade" (Eagleton, 2005, p. 27). 
apropriação pessoal e que foge aos objetivos da obra do autor, que trabalha no campo da crítica literária, mas cujo trabalho oferece importantes insights para o campo das ciências sociais e, especificamente, neste caso, para o campo da educação e, mais centralmente, para o campo do currículo.

Eagleton (2005) busca demonstrar que parte dos estudos culturais, em sua atual fase, de certo modo, termina por fundir-se com valores da cultura de mercado. De acordo com o autor, o modernismo e o que ele denomina de "alta teoria cultural" compartilhavam interesses e estavam preparados para avançar em novos territórios e para trazer à tona questões de suma importância. Naquele momento, os estudos culturais forjaram novos conceitos e novas abordagens. Trataram de questões políticas, sexuais, éticas, econômicas, da linguagem e cultura, da psique e da civilização humana. Diferentemente, para o autor, a teoria cultural de hoje:

Não gosta da idéia de profundidade, e fica perturbada quando se trata de fundamentos. Estremece diante da noção de universal e desaprova perspectivas abrangentes ambiciosas. [...] ela acredita no local, no pragmático, no particular. E, com este devotamento, ironicamente, difere muito pouco da erudição conservadora que detesta, e que também só acredita no que pode ver e pegar (Eagleton, 2005, p. 106).

Para o autor, a teoria cultural dos anos 1960 e 1970, que propunha demolir o realismo, não percebeu que a própria civilização ocidental estava se tornando não realista. Era a própria realidade que assumia contornos não realistas, quando o sistema "tornava-se cada vez mais dependente, em suas operações cotidianas, de mito e fantasia, riqueza ficcional, exotismo e hipérbole, retórica, realidade virtual e mera aparência” (Eagleton, 2005, p. 101).

Assim, quando os estudos culturais, em um segundo momento, se concentraram em demonstrar o fugidio, o efêmero, a aparência, a superfície das coisas, a indústria cultural se adiantava, via espetáculos políticos e reality-shows da televisão, por exemplo. Nesse momento, valores se confundem e se nivelam no que é conhecido como economia de mercado.

Esse seria, de maneira bem geral, o tom da crítica de Eagleton. Contudo, alguns dos problemas mais específicos por ele levantados podem trazer novos elementos para a discussão no campo educacional.

Em primeiro lugar, destaca-se a ênfase com que Eagleton reafirma uma importante contribuição da teoria cultural - o reconhecimento da 
importância da cultura popular, em um contexto em que o pensamento acadêmico dominante ignorava a vida diária das pessoas comuns. Nesse mesmo sentido, o autor salienta a importância do reconhecimento de que a vida humana é perpassada por desejos e fantasias e que a sexualidade é um importante aspecto a ser também estudado. Para o autor, essas temáticas ajudaram a demolir um importante dogma puritano de que seriedade e prazer são coisas distintas e que se opõem. Nas palavras de Eagleton, "o puritano confunde prazer com frivolidade porque confunde seriedade com solenidade" (Eagleton, 2005, p. 18). Desse modo, descobrir modos de tornar a vida mais prazerosa "é assunto sério". ${ }^{4}$

Essas são idéias que há muito tempo vêm circulando no campo educacional e no campo curricular. Os chamados currículos tradicionais, alicerçados em habilidades cognitivas, trabalhavam com idéias como verdade e razão e, nesse sentido, ignoravam que prazer, fantasias e desejos estão imbricados em tudo o que fazemos. Da mesma forma, o conhecimento escolar se distanciava das experiências do dia-a-dia. O estudo da vida diária do homem comum, a valorização de suas práticas culturais, introduziu no campo do currículo a preocupação pela sintonia entre as práticas pedagógicas e a realidade cotidiana dos alunos.

Neste ponto, pode-se argumentar que muitas escolas já estão buscando se conectar com a realidade dos alunos, ao trazer para seu interior a música, a dança, enfim, uma série de elementos culturais, que fazem parte da vida diária dos alunos. Inegavelmente, há hoje nas escolas uma preocupação com o prazer que as atividades escolares possam proporcionar aos seus estudantes. Contudo, em muitos casos, parece que vem sendo confundido o prazer advindo de uma conquista, de uma descoberta, de uma experiência estética, de uma comunhão de idéias, com o prazer hedonista que é apregoado e divulgado pela sociedade de consumo. De acordo com Eagleton, para o velho capitalismo o prazer era perigoso, porque uma vez descoberto levaria ao desinteresse pelo mundo do trabalho. No capitalismo atual, o prazer torna-se um importante aspecto do consumo. É o prazer que coloca a satisfação pessoal, a gratificação imediata, a auto-indulgência como elementos fundamentais da vida cotidiana (Eagleton, 2005, p. 18-19). Torna-se, pois, importante uma

4 Para o autor, no entanto, "descobrir como tornar a vida mais prazerosa nem sempre é prazeroso. Como toda pesquisa científica, requer paciência, autodisciplina e uma inesgotável capacidade de se aborrecer" (Eagleton, 2005, p. 18). 
reflexão sobre o sentido do prazer que as atividades escolares têm buscado. Seria o prazer trazido pela compreensão de uma questão? pela descoberta de uma nova possibilidade de conhecer o mundo? pela maior possibilidade de interagir com o outro através da compreensão de sua realidade? pelo melhor entendimento dos problemas que nos rodeiam? pela realização, com sucesso, de uma atividade?

Parece que a escola tem tido dificuldades em tornar os conteúdos escolares prazerosos pelo seu significado intrínseco. Na verdade, é preciso de um currículo bem organizado e bem orquestrado para que os alunos possam sentir prazer com a experiência estética da literatura, com a harmonia de uma forma geométrica e com a beleza da natureza e a complexidade do mundo social.

Em segundo lugar, Eagleton enfatiza que, ao lado da importante contribuição sobre gênero e sexualidade, os estudos culturais trazem para o centro da discussão a realidade opressiva de diferentes segmentos da população. É que os chamados “estudos pós-coloniais", introduzidos pelos estudos culturais, buscam resgatar o que estava à margem e nas margens. Apesar dos avanços trazidos pelos estudos pós-coloniais, Eagleton vai problematizar seus desdobramentos em dois sentidos. Primeiramente, o autor observa que, para o pensamento pós-moderno contemporâneo, que orienta algumas análises dos estudos pós-coloniais, a vida social majoritária pode ser de pouco valor (Eagleton, 2005, p. 27). Para o autor, se as minorias parecem mais vibrantes que a maioria, é importante lembrar que foram as maiorias que lutaram contra o colonialismo nas lutas nacionalistas revolucionárias, que foram as maiorias que derrubaram governos totalitários em diferentes países. Se os destituídos são marginais, os mal pagos não são centrais nem marginais. Eles se constituem na imensa maioria de trabalhadores, que fazem a máquina funcionar (Eagleton, 2005, p. 36-37). Se as margens são pensadas em termos de minoria, essa grande maioria fica obscurecida. Para Eagleton, esse problema ocorre porque grande parte da produção dos estudos culturais vem dos Estados Unidos e termina por trazer a marca do etnocentrismo daquele país. É que, para o americano, minoria significa ser hispânico ou afro-descendente, o que não inclui o povo de Bangladesh ou de outras nações, em que a grande maioria vive em extrema pobreza (Eagleton, 2005, p. 36-37).

Em um segundo sentido, e de uma forma irônica, Eagleton também polemiza a questão da inclusão. Para ele, o problema está em quem irá 
decidir quem será incluído. Em um contexto, em que segmentos inteiros da classe trabalhadora têm sido excluídos, o pós-modernismo ${ }^{5}$ deposita toda sua fé no pluralismo - em uma ordem social que seja tão diversificada e inclusiva quanto possível. ${ }^{6}$ Evidenciando como a inclusão pode se tornar um conceito vazio, o autor mostra que, em princípio, nada é mais inclusivo do que o capitalismo na sua sede pelo lucro, pois explora igualmente a todos, sem distinção e discriminação, demonstrando grande imparcialidade diante dos consumidores, usem eles terno e gravata, turbantes coloridos ou apenas um pano em volta dos quadris. Assim:

No espírito generosamente humano do poeta antigo, nada do que é humano é estranho a esse sistema. Em sua caça ao lucro, viaja qualquer distância, agüenta qualquer privação, mora com os companheiros mais insuportáveis, sofre as abomináveis humilhações, tolera o papel de parede do mais extremo mau gosto e alegremente trai seu parente mais próximo. [...] Tem o mesmo desprezo por hierarquias que um adolescente truculento e pega e mistura coisas com o mesmo zelo de um jantar americano (Eagleton, 2005, p. 35).

Essas idéias provocativas de Eagleton permitem levantar algumas questões para o campo do currículo. É que, de fato, há na escola pública uma grande maioria que tem recebido pouca atenção na produção acadêmica. O campo do currículo volta-se com mais interesse para a questão das diferenças, esquecendo-se de que uma grande maioria compartilha problemas comuns. ${ }^{7} \mathrm{O}$ que se quer dizer é que a criança e o adolescente, das camadas populares, que pertencem a essa imensa maioria e que não apresentam diferenças tão visíveis, têm ficado fora de foco (ou em segundo plano). ${ }^{8}$ Vão deixando de ser objetos atraentes para os

5 É importante destacar que Eagleton quase nunca usa o termo pós-estruturalismo. Com isso, quer distinguir trabalhos de autores como Foucault, Derrida, Lacan e Barthes da produção de grande parte de seus seguidores contemporâneos que, para ele, banaliza o trabalho dos primeiros e, diferentemente daqueles, não apresenta contribuições teóricas relevantes.

6 Nesse ponto, o autor ironiza dizendo que essas idéias são tão óbvias que "não contêm muito do que o Príncipe Charles pudesse discordar" (Eagleton, 2005, p. 34).

7 É claro que existem conflitos e contradições no interior tanto das maiorias como das minorias.

8 Não está sendo negada aqui a importância de estudos e de políticas públicas que busquem a inclusão de todos os grupos ou pessoas em situação de desvantagem. 
intelectuais da educação, porque estudar a "limitada vida cotidiana" dessa grande parcela da população, cheia de privações, mas sem grandes desvios das normas sociais, parece não ter grande apelo acadêmico. ${ }^{9}$ Assim, discutir os percursos escolares, as formas de aprendizagens, os obstáculos que o currículo oferece a essas crianças e jovens parece ser um assunto já ultrapassado. Há também pouca disposição em investigar as diferenças nas maiorias, porque essas não são, muitas vezes, auto-evidentes, trabalho este que exigiria maior esforço acadêmico. Parece que é tarefa árdua e pouco estimulante ir além das aparências e das superfícies, em um mudo em que fatos sociais são transformados em espetáculo, em que as aparências, o fugidio e o efêmero são celebrados.

Em terceiro lugar, de acordo com Eagleton, quando o pósmodernismo celebra as diferenças, na realidade o que está sob ataque são as normas, uma vez que as normas é que são opressivas, porque não dão espaço para a diferença. Contudo, pondera o autor, as normas, além de inevitáveis, são uma certa ordenação ao mundo. A própria linguagem tem uma dimensão normativa e, em um mundo de puras diferenças, seria impossível alguém dizer algo inteligível. Na verdade, argumenta Eagleton, essa aversão à norma, nos trabalhos dos pós-modernistas contemporâneos, está deslocada no tempo, ${ }^{10}$ uma vez que o que está sob ataque é a norma defendida por uma burguesia que não existe mais. Com base em Perry Anderson, Eagleton afirma que essa burguesia, que defendia valores morais e determinados padrões culturais, foi substituída por uma outra, hoje constituída e representada por dirigentes insípidos, presidentes atores, princesas vedetes, num contexto em que as práticas de suborno fazem parte do dia-a-dia, assim como as conexões com pistoleiros de aluguel (Eagleton, 2005, p. 31). De acordo ainda com o autor, nos dias atuais, quem diz tudo é permissível; são os operadores da bolsa, os executivos

9 Os que pensam que existem apenas "eles" e "nós”, margens e maiorias, são justamente aqueles que "suspeitam profundamente de oposições binárias” (Eagleton, 2005, p. 37).

10 Para o autor, “O pós-modernismo às vezes parece se comportar como se a burguesia clássica estivesse viva e saudável. Gasta muito tempo atacando verdade absoluta, objetividade, valores morais atemporais, pesquisa científica e crença no progresso histórico. Põe em questão a autonomia do indivíduo, as normas sociais e sexuais inflexíveis e a crença de que o mundo está assentado em fundamentos sólidos. [...] Todos estes valores fazem parte do mundo burguês em declínio. [...] Isto não significa dizer que essas crenças ainda não tenham força. Fazem o maior sucesso em lugares com Ulster e Utah. Mas ninguém em Wall Street, e pouca gente em Fleet Street, acredita em verdade absoluta e em fundamentos inquestionáveis" (Eagleton, 2005, p. 33). 
das grandes corporações e os editores de jornais. Nesse sentido: "A norma agora é dinheiro, mas como o dinheiro não tem absolutamente nenhum princípio ou identidade própria, não é norma nenhuma. É totalmente promíscuo, e acompanhará, aquele que der maior lance" (Eagleton, 2005, p. 32).

Realmente, hoje, as normas têm sido vistas como opressivas, pois buscam a uniformidade em um mundo de diferenças. Mas as normas são fundamentais no campo do currículo. Normas que definam o que é significativo estudar. Normas que definam alguns princípios para o ensino, como a necessidade de organização e sistematização dos conteúdos. Normas que definam o papel do professor. Normas que definam valores éticos a serem preservados pela escola. E mesmo normas que definam o que é permitido e o que não é permitido fazer na escola. $\mathrm{O}$ medo das normas cria um problema paradoxal, ou seja, a dificuldade em impor limites e a revolta contra certos tipos de comportamentos. É como se os alunos, de antemão ou naturalmente, soubessem o que se pode e o que não se pode fazer na escola. Tem sido criticada a desvalorização das normas sociais, e, ao mesmo tempo em que essas normas são questionadas, fica difícil distinguir o que deve permanecer e o que deve ser banido. Nesse cenário, a escola precisaria discutir que normas sociais são importantes para seu funcionamento democrático, que normas facilitam as relações interpessoais, que normas criam um clima adequado para o desenvolvimento de aprendizagens significativas.

Em quarto lugar, Eagleton questiona vertentes mais contemporâneas dos estudos culturais pela rejeição à verdade, virtude, objetividade e moralidade. Para o autor, alguns teóricos dessas vertentes não se diferem significativamente de empresários e banqueiros, pois poucos deles acreditam em verdades absolutas e em fundamentos inquestionáveis. Da mesma maneira, a grande maioria dos cientistas, para Eagleton, é bastante cética em relação à ciência, considerando-a mais como uma questão de acerto e erro do que de elaboração de verdades. Do mesmo modo, os políticos e homens de negócio também não acreditam em valores morais. É que as práticas capitalistas não respeitam fronteiras de espécie alguma e não se detêm por escrúpulos ou valores morais. É interessante observar que: "Tanto os pós-modernos quanto os neoliberais suspeitam de normas públicas, valores intrínsecos, hierarquias dadas, padrões de autoridade, códigos consensuais e práticas tradicionais. Só que os neoliberais admitem que rejeitam tudo isso em nome do mercado" (Eagleton, 2005, p. 59). 
Ironicamente, afirma ainda o autor, em um mundo sem fronteiras, para o capital, os estudos culturais celebram o local. Contudo, é interessante destacar que "os ricos têm mobilidade, enquanto os pobres têm localidade" (Eagleton, 2005, p. 38). Enquanto a pobreza é um problema global, a riqueza torna-se mais localizada. A partir dessas observações, torna-se possível afirmar que essa paisagem só será transformada quando solidariedade for um valor global e não uma ação local e paliativa.

Em quinto lugar, de acordo com Eagleton, se na modernidade o foco das discussões sociais esteve centrado na nação e nas classes sociais, nos estudos culturais, a etnicidade assume um lugar privilegiado. Como etnicidade é basicamente uma questão cultural, a mudança de foco desloca também o interesse da política para a cultura. ${ }^{11}$

Essa mudança se associa aos processos de transformação do capitalismo. A queda na taxa de lucro pela redução gradual da expansão do capitalismo no pós-guerra, devido à intensificação da concorrência internacional, levou o sistema a passar por grandes modificações. Nesse processo de renovação da organização do trabalho e das relações de produção, os investimentos deixaram o setor industrial pelos atrativos campos das comunicações, dos serviços e das finanças. A indústria cultural agiganta-se à medida que os grandes negócios se tornam culturais, cada vez mais baseados em imagens, embalagem e apresentações (Eagleton, 2005, p. 89). Se, em épocas passadas, os movimentos nacionalistas discutiam a proliferação da pobreza, os movimentos radicais do Ocidente, nos anos 1960, colocavam problemas que advinham do progresso e da prosperidade. Era o mundo burocraticamente administrado, as aprendizagens empacotadas e o poder da mercadoria que estavam sendo questionados. Hoje, os estudos culturais, ao tratar da cultura apenas em termos de prazer, desejo, linguagem mídia, corpo e gênero, correm o perigo eles próprios de tornarem-se uma mercadoria, com grande apelo para os intelectuais cansados de temas desgastados como classe social, pobreza e miséria. Parece que: "A emancipação que não havia sido conquistada nas ruas e fábricas podia ser alcançada, em vez disso, em intensidades eróticas ou no significado flutuante. Discurso e desejo vieram ocupar os lugares do Godard e do Guevara que haviam falhado" (Eagleton, 2005, p. 51).

11 Eagleton afirma que, há muito, a esquerda cultural havia desistido até mesmo de mencionar o capitalismo. "Falar de gênero e etnicidade estava bem; mas falar de capitalismo era totalizante ou “economicista” (Eagleton, 2005, p. 83). 
À medida que a indústria cultural torna-se tão lucrativa, em que o virtual substitui o real, em que o espetáculo político corrói a democracia, cultura passa a significar o que era antes descrito como produção econômica, hegemonia política, propaganda ideológica. Cultura passa a ser um universal, quando os intelectuais do campo dos estudos culturais refutam idéias universalizantes. ${ }^{12}$ Segundo Eagleton, nesse cenário, o pensamento planetário ou qualquer coisa que nos una, que busque semelhanças, parece danoso, quando a "diferença" torna-se a nova palavra de ordem "num mundo crescentemente submetido às mesmas indignidades de morte por fome e doença, cidades clonadas, armas mortais e a rede de televisão CNN" (Eagleton, 2005, p. 75). Para o autor, é realmente irônico que a diferença seja tão celebrada por quem quer "apagar as distinções entre imagem e realidade, verdade e ficção, história e fábula, ética e estética, cultura e economia, arte culta e arte popular, esquerda e direita políticas" (Eagleton, 2005, p. 75).

Em síntese, Eagleton salienta as grandes contribuições dos estudos culturais, trazidas pelo feminismo, pelos estudos pós-coloniais, pela teoria da recepção, pelas discussões sobre as várias formas em que o poder se manifesta, mas é extremamente crítico às vertentes dos estudos culturais que caem em um relativismo extremo. O que está sendo advogada é a idéia do perigo de se reduzir toda a realidade à cultura, desconsiderando questões como economia e política. A pobreza, o desemprego, a fome e o sofrimento, as injustiças não podem ser relativizados e são realidades que exigem posicionamentos morais. Educadores e curriculistas precisam estar cientes de que a cultura responde a grande parte dos problemas sociais, mas à cultura se mesclam questões econômicas e sociais e políticas, que, muitas vezes, têm maior peso e maior poder explicativo para sérios problemas vivenciados na contemporaneidade.

\section{O QUe fazer?}

Só nesta semana, entre várias notícias sobre o baixo desempenho escolar, em uma reportagem da revista Época de 23 de abril de 2007, e no edital do jornal Folha de S.Paulo, do dia 22 de abril, também desse ano, há

12 Contraditoriamente, a teoria cultural rejeita a idéia de idéias universalizantes, em uma época em que as corporações internacionais dominam todo o globo. Segundo Eagleton, "exatamente no ponto em que começamos a pensar pequeno, a História começa a agir grande"(Eagleton, 2005, p. 107) . O autor refere-se a esse momento histórico em que "a grande narrativa da globalização capitalista e a reação destrutiva que traz em seu rastro desdobram-se por todo o planeta" (Eagleton, 2005, p. 107). 
referências a dois grupos que se pronunciam, lançam metas e objetivos para a educação brasileira. O primeiro deles, "Todos pela Educação", 13 citado pelo edital do jornal Folha de S.Paulo, tem como patrocinadores o Instituto Ayrton Sena, a Fundação Educar, a Fundação Bradesco, a Fundação Itaú Social, o Banco Real, a Rede Gerdau, a Fundação Roberto Marinho, o Santander, a Suzano Papel e Celulose, e conta com entidades estudantis e de professores, de instituições universitárias e de várias organizações e organismos nacionais e internacionais. Esse grupo propõe metas para a educação, a serem atingidas até o bicentenário da independência do Brasil, que vão desde a alfabetização de todas as crianças até os 8 anos de idade, como também incluem a universalização do ensino médio. $\mathrm{Na}$ mesma direção, a revista Época mostra que a "Campanha Nacional pelo Direito à Educação" 14 realiza "o levantamento mais abrangente do que seria preciso para a educação brasileira ter um mínimo de qualidade" (Época, 2007, p. 97). Essa campanha, que abrange quase 200 das principais entidades e fundações ligadas à educação, é financiada pela Oxfan (que reúne a coordenação de 13 organizações internacionais), pela Actionaid (ONG fundada no Reino Unido), pela Novib (ONG holandesa que faz parte da Oxfan) e pela Plan Internacional (ONG também do Reino Unido).

É surpreendente o número de empresas e de organizações nacionais e internacionais que se voltam para a educação brasileira, neste momento. Seria oportuno perguntar: O que elas têm em comum? Sem dúvida, compartilham o interesse pela manutenção do capitalismo, a preocupação em produzir mão-de-obra capaz de garantir os interesses do sistema, a aversão por conflitos e lutas que possam desestabilizá-lo.

Com base nessa realidade, não seria importante que os acadêmicos se organizassem também em defesa da educação, mas em perspectivas distintas dessas organizações? Sem dúvida, há muito o que se fazer; poderse-ia começar conclamando os curriculistas a repensarem o currículo escolar. Podem começar questionando seus próprios trabalhos, argüindo: Com que objetivos estudo esta questão? A quem interessa? Às crianças e jovens da escola publica ou a meus colegas acadêmicos, a quem quero demonstrar erudição, originalidade e conhecimento?

Para maiores informações, consultar: <http://www.todospelaeducacao.org.br>.

Para informações sobre essa campanha, incluindo patrocinadores e metas, consultar: $<$ http://www.campanhaeducacao.org.br $>$. 
Afinal, levantar questões sobre questões levantadas tem sido uma prática comum aos pós-modernistas. Pode-se afirmar que, em parte da produção acadêmica sobre currículo, são freqüentes as metaquestões. ${ }^{15}$ No entanto, não seria oportuno, ao levantar questões sobre questões, também tentar respondê-las? Assim, quando se pergunta "Este conteúdo tem valor?", não é suficiente apenas indagar "o que se quer dizer com valor"? Da mesma forma, quando se indaga "Esta é uma forma democrática de se organizar uma atividade curricular?", não é suficiente retornar à pergunta argüindo "o que é atividade curricular" ou "o que se entende por forma democrática"? Tanto as primeiras perguntas quanto as segundas precisariam ser respondidas. Apenas levantar questões sobre questões postas não tem ajudado a pensar a contingência e as dificuldades de se tornar humano em um mundo que, cada vez menos, crê na possibilidade de justiça e que duvida de valores e sentimentos como solidariedade e amor.

Finalizando, pode-se dizer que algumas idéias de Eagleton foram aqui retomadas porque elas recolocam velhas questões no campo do currículo, ou seja, a seleção de temáticas que possibilitem maior consciência sobre as injustiças sociais, a organização de conteúdos que ajudem a compreender a complexidade do mundo em que vivemos, a valorização da cultura do aluno conjugada à preocupação em introduzir produções culturais do campo científico e artístico, que dilatem a maneira de ver e estar no mundo.

Pode-se observar que algumas das produções atuais do campo do currículo, sob a influência dessas vertentes consideradas mais radicais dos estudos culturais, pouco têm acrescentado à prática escolar. A sua preocupação com a diferença leva a um discurso acadêmico, em que, muitas vezes, a própria diferença na forma e conteúdo da produção não tem possibilitado um estranhamento, que leve a novas interpelações sobre questões naturalizadas pelo senso comum pedagógico. A originalidade, na produção acadêmica curricular, significaria muito mais o tratamento de "velhos" problemas práticos da educação em uma abordagem que permita ver essas questões sob novos ângulos, abrindo caminhos para novas formas de pensamento e de ação. Talvez a originalidade no campo do currículo esteja na produção de discursos cujos significados possam

15 Eagleton chama a atenção para o fato de os pós-modernistas utilizarem exaustivamente as metaquestões em seus trabalhos. 
oferecer alternativas para um cotidiano marcado pela superficialidade da propaganda e do apelo ao consumo. Nesse sentido, é preciso examinar com cautela as idéias que circulam nesse campo, pois algumas delas parecem estar se alinhando à arquitetura dessa sociedade de consumo, em que a valorização do efêmero, do instantâneo, do que causa prazer imediato, reproduz a exclusão social de forma insidiosa e brutal.

\section{Referências}

ARANHA, A. O que as escolas precisam aprender. Época, Rio de Janeiro, n. 466, p. 90-98, abr. 2007.

BOURDIEU, P. Os usos sociais das ciências - por uma sociologia clínica do campo científico. São Paulo: UNESP, 2004.

BOURDIEU, P. As regras da Arte. São Paulo: Schwarcz Editora, 1996.

BRASIL. Secretaria de Educação Fundamental. Parâmetros Curriculares Nacionais. Brasilia: MEC/SEF, 1998.

EAGLETON, T. Depois da teoria - um olhar sobre os estudos culturais e o pósmodernismo. Rio de Janeiro: Civilização Brasileira, 2005.

EDITORIAL. O básico em educação. Folha de S.Paulo, São Paulo, n. 28.508, p. A 2, 22 abr. 2007.

MOREIRA, A. F. B. Currículos e programas no Brasil. Campinas: Papirus, 1990.

Recebido em: 20/03/2007

Aprovado em: 26/042007 